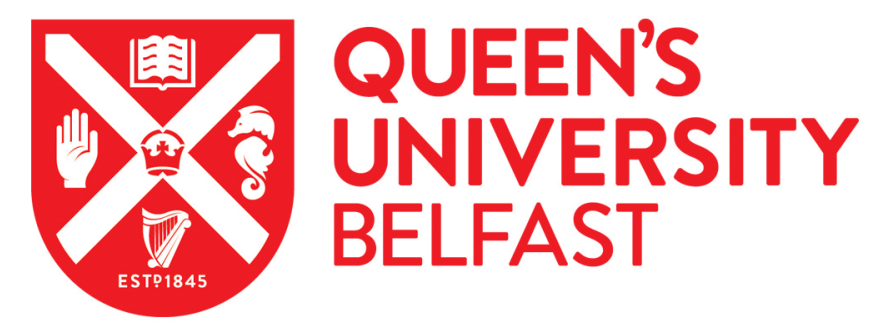

\title{
Integrated and implicit: How residents learn CanMEDS roles by participating in practice
}

Renting, N., Raat, A. N., Dornan, T., Wenger-Trayner, E., van der Wal, M. A., Borleffs, J. C. C., Gans, R. O. B., \& Jaarsma, A. D. C. (2017). Integrated and implicit: How residents learn CanMEDS roles by participating in practice. Medical Education.

Published in:

Medical Education

Document Version:

Peer reviewed version

Queen's University Belfast - Research Portal:

Link to publication record in Queen's University Belfast Research Portal

Publisher rights

(c) 2017 John Wiley \& Sons Ltd and The Association for the Study of Medical Education This work is made available online in accordance with the publisher's policies. Please refer to any applicable terms of use of the publisher.

\section{General rights}

Copyright for the publications made accessible via the Queen's University Belfast Research Portal is retained by the author(s) and / or other copyright owners and it is a condition of accessing these publications that users recognise and abide by the legal requirements associated with these rights.

Take down policy

The Research Portal is Queen's institutional repository that provides access to Queen's research output. Every effort has been made to ensure that content in the Research Portal does not infringe any person's rights, or applicable UK laws. If you discover content in the Research Portal that you believe breaches copyright or violates any law, please contact openaccess@qub.ac.uk. 
Integrated and implicit: How residents learn CanMEDS roles by participating in practice.

Nienke Renting ${ }^{1}$

A.N. (Janet) Raat ${ }^{2}$

$\operatorname{Tim}_{\text {Dornan }}^{3}$

Etienne Wenger-Trayner ${ }^{4}$

Martha A. van der Wal ${ }^{1}$

Jan C. C. Borleffs ${ }^{1}$

Rijk O.B. Gans ${ }^{5}$

A. Debbie C. Jaarsma ${ }^{1}$

${ }^{1}$ Center for Education Development and Research in Health Professions (CEDAR),

University of Groningen and University Medical Center Groningen, Groningen, the

Netherlands

${ }^{2}$ Research Centre for Talent Development in Higher Education and Society, Hanze University of Applied Sciences, Groningen, The Netherlands

${ }^{3}$ Centre for Medical Education, Queen’s University Belfast, UK

${ }^{4}$ University of Brighton, UK

${ }^{5}$ Internal Medicine Department, University of Groningen and University Medical Center Groningen, the Netherlands 


\section{Abstract}

\section{Context}

Learning outcomes for residency training are defined in competency frameworks such as the CanMEDS, which ultimately aim to prepare residents better for their future tasks. Although residents' training relies heavily on learning through participation in the workplace under the supervision of a specialist, it remains unclear how the CanMEDS framework informs practice-based learning and daily interactions between residents and supervisors.

\section{Objectives}

This study aims to explore how the CanMEDS framework informs residents' practice-based training and supervisory interactions.

\section{Methods}

Constructivist grounded theory guided iterative data collection and analyses. Data were collected by direct observations of residents and supervisors, combined with formal and field interviews. We progressively arrived at an explanatory theory by coding and interpreting the data, building provisional theories and continuous conversations. Data analysis drew on sensitising insights from Communities of Practice theory, which provided this study with a social learning perspective.

\section{Results}

CanMEDS roles occurred in an integrated fashion and usually remained implicit during interactions. The language of CanMEDS was not adopted in clinical practice, which seemed to impede explicit learning interactions. The CanMEDS framework seemed only one of many factors of influence in practice-based training: patient records and other documents were highly influential on daily activities and did not always correspond with CanMEDS roles. Additionally, residents' position seemed too peripheral to learn certain aspects of the Health Advocate and Leader roles.

\section{Conclusions}

The CanMEDS framework did not really guide supervisors' and residents’ practice or interactions. It did was not explicitly used as a common language to talk about resident performance and roles. It therefore remains questionable to what extent CanMEDS actually helps improve residents’ learning trajectories and conversations between residents and 
supervisors about their progress. This study highlights that the reification of competency frameworks into the complexity of practice-based learning is not a straightforward exercise. 


\section{Introduction}

Medical specialists help residents learn the roles and behaviours of their specialty during postgraduate training by allowing them to participate in their patient care practice. In order to direct residents' learning in this complex setting, professional roles are defined in competency frameworks such as the CanMEDS. ${ }^{1,2}$ By focusing on the ultimate outcomes of physician performance, competency-based medical education aims to produce professionals who are more responsive to the needs of society. ${ }^{3-5}$ CanMEDS' slogan 'Better standards. Better physicians. Better care.' illustrates its implicit assumption that assessing competencies will improve physician performance. ${ }^{1}$ Within an increasingly influential paradigm which considers training programmes as accountable to society, competency frameworks are commonly advocated as assessment standards for professional performance. ${ }^{6-9}$ Understanding that assessment drives learning, ${ }^{10}$ a lot of valuable effort has been directed towards the development of instruments to assess the performance of residents. How residents are expected to learn to take on the CanMEDS roles, however, is not specified in the framework. Little is currently known about how residents actually learn CanMEDS roles from their practice-based training.

There is a well-established understanding of the significance of practice-based learning for residents. Residents gradually take on increasingly important roles in a patient care practice, with support from their supervisors. ${ }^{11,12}$ Many CanMEDS roles, such as Health Advocate, Leader, Communicator and Collaborator, are considered roles which can only be learnt by participating in the workplace. ${ }^{13,14}$ A growing body of literature about practice-based learning is beginning to unravel important, often tacit, learning processes. ${ }^{15-17}$ Teunissen et al. describe how clinical activities are the starting point for residents' learning, followed by processes of 'interpretation' and 'construction of meaning', during which interactions with supervisors and others are important. ${ }^{18}$ Social theories of learning, particularly Communities of Practice, provide us with the understanding of the significance of social participation for practice-based learning. ${ }^{19}$ Communities of Practice theory holds that in practice-based learning, the practice itself has most influence on what is being learned, as opposed to any outside definition of competence. The way CanMEDS roles are enacted in practice would therefore be of major importance on how residents learn them. Whether competency frameworks such as the CanMEDS actually add anything to practice-based learning might therefore largely depend on how they are adopted in clinical practice by residents and their supervisors. 
Although we could not find any studies that specifically explore how the CanMEDS roles and the behaviours and they promote come to life in practice-based learning outside assessment situations, some studies revealed certain conceptual issues regarding assessment that could be transferred to daily practice-based learning. Despite intensive efforts, developing quantified, standardized measures of all aspects of physician performance has turned out to be difficult to realize. ${ }^{20-23}$ Assessment instruments often remain unreliable, unable to distinguish between the roles and achieve a balanced representation of the competency framework. ${ }^{6,24}$ A possible explanation for these struggles is that supervisors have different, more complex conceptions of competence than what is described in competency frameworks. In a previous study, we found that supervisors defined CanMEDS roles more in terms of their sociohistorical backgrounds, personal experiences, and beliefs than on how the roles are described on paper. ${ }^{25}$ Another study showed that supervisors have a complex and holistic view of competence, in which individual CanMEDS roles cannot be distinguished from one another. ${ }^{23}$ Supervisors view residents' competence in more complex ways than the 'simple linear addition' of performance on different CanMEDS roles. ${ }^{23}$ It is possible that these differences in conceptions of competence affect residents’ practice-based learning, although it remains unclear how.

This grounded theory study aimed to develop an explanatory theory of how competency frameworks, such as CanMEDS, influence daily practice-based learning.

\section{$\underline{\text { Methods }}$}

\section{Ethical Approval}

The authors obtained approval for this study from the ethical review board of the Dutch Association of Medical Education [2015/502]. Informed consent was obtained from all participating and observed residents, supervisors, nurses and patients, and confidentiality was guaranteed.

\section{Conceptual Orientation}

This study approached practice-based learning from a sociocultural perspective, which acknowledges learning as the outcome of social processes. ${ }^{26,27}$ Wenger's theory of Communities of Practice applies well to the complex setting of residents' practice-based 
learning as judged by researchers' increasing use of it in this domain. ${ }^{19,}{ }^{27-30}$ In Communities of Practice theory, ${ }^{19}$ learning is described as a result of social participation in a professional community's practice. A Community of Practice is described as a group of people who have developed a shared practice over time by working and learning together.

Communities of Practice theory ${ }^{19}$ provided sensitising insights for the constructivist grounded theory methodology adopted for this study. These related to identity formation, negotiation of meaning, and the shared regime of competence of a Community of Practice. The course of learning followed by residents in their participation in different departments and hospitals, shapes their identities as medical specialists and gives meaning to medical practice and procedures. This shared practice is embodied in a regime of competence that usually remains tacit. A competency framework that defines professional roles can be considered as a formal description of the 'ideal' regime of competence of a clinical community. Despite this formal description not being part of the sociocultural history of that community it is a potentially influential artefact. How CanMEDS roles are given expression in a clinical workplace depends on a process called negotiation of meaning, through which community members make sense of an artefact of the community for their specific context.

\section{Study design}

For this grounded theory ${ }^{31}$ study, data were collected and analysed iteratively. Qualitative data were collected through direct observations of daily interactions between supervisors and residents, brief field interviews and in-depth formal interviews. These methods align particularly well with Communities of Practice theory, given it was developed on ethnographic and anthropological foundations. ${ }^{19}$

\section{Context}

Data for this study were collected at Internal Medicine residency programmes in the Netherlands. In 2009, the Dutch Internists Association initiated to use CanMEDS as a foundation for the training programmes on a national level. This was an important shift from focusing solely on knowledge about diseases to incorporating generic competencies in the training programme. The association expected this innovation to ease the transition from graduate training and prepare internal medicine residents better for their future careers. Learning goals, teaching methods and assessments are prescribed for each CanMEDS role. ${ }^{32}$ 
This study was performed in the Internal Medicine departments of three hospitals: a University Medical Centre and two affiliated teaching hospitals. Patients were treated by residents under the supervision of attending internists on medical wards, medium care units, emergency rooms and outpatient clinics. Around 20-25 patients in a ward were allocated between two to three residents under the supervision of one attending physician.

The boundary of a Community of Practice, which defines who is a member and who is not, is typically dynamic and implicit. ${ }^{19}$ For this study, a Community of Practice was described as a team of clinical supervisors, residents, interns, nurses, and patients on a ward or unit, who collaborated together in the practice of patient care. Clinical supervisors were the core group of communities in which residents were active participants. Interns and nurses were more peripheral participants. Patients', who came and went frequently, had a more transactional relationship with these Communities of Practice.

\section{Research team}

The team comprised medical education researchers (NR, AR, MW, DJ, TD), internal medicine specialists with extensive experience in supervising residents (RG, JB, TD) and a social learning theorist (EW). RG, JB and DJ have all been closely involved in the design and implementation of CanMEDS curricula. RG and JB were two of the designers of the CanMEDS-based postgraduate Internal Medicine training programme that was the context of this study. TD had a more critical stance towards the utility and necessity of competency frameworks in the team's scholarly discussions. ${ }^{33}$ The founder of Communities of Practice Theory, EW, used his expertise in social learning and his relative unfamiliarity with clinical workplace settings, to discuss the meaning of our data critically. The observers were an educationalist (NR) and a psychologist (MW), both $\mathrm{PhD}$ students in the field of medical education, which supported an open-minded approach towards the clinical workplace and particular attentiveness to situations influential for residents’ learning.

\section{Recruitment of participants}

The study was introduced to residents and supervisors with an email and a short presentation, informing them about the study. Participants were asked to volunteer. Additional participants were recruited by follow-up contact with the wards. Initially, supervisors who residents indicated were especially influential for their learning were approached to participate. 
Participants likely to offer a contrasting perspective to preceding participants were purposely selected by theoretical sampling until the sample was judged to be sufficient. For instance, the initial group of participating supervisors were relatively unfamiliar with the CanMEDS framework: therefore, supervisors who were more aware of the CanMEDS were actively recruited. To established a balanced participant group, supervisors and residents from various internal medicine-based specialties, such as nephrology and endocrinology, and with different experience levels were recruited (Table 1).

\section{Data collection}

\section{Direct Observations}

We observed the participants on duty in their wards, emergency rooms and outpatient clinics. While observing, we dressed in hospital uniform. The observers used the marginal-participant technique, which meant they blended in and tried to avoid influencing the social setting as much as possible. ${ }^{34}$ They made detailed notes of the following to facilitate inductive analysis: actions, outlines of conversations, positioning and set-up of rooms, body language, facial expressions and emotions. These detailed notes allowed to analyse, for instance, participants' verbal messages in conjunction with their about body language, tone of voice and facial expressions. The observers did not know the residents or supervisors they observed. NR and MW started by individually observing different wards and discussing their findings. When sharing notes after several days of observations and reflecting on their impressions, they found enough similarity in what they had observed for just one observer (NR) to continue the study. The iterative process of discussing notes and collecting data helped reflexively to identify preconceptions reflexively, put the findings in a broad context and informed further data collection.

\section{Field interviews}

At suitable moments during the direct observations, the observers conducted field interviews by asking clarifying questions (i.g. what a certain procedure meant), reasoning questions (i.e. why a supervisor intervened in a conversation), and circumstantial questions (i.e. how the researcher's presence influenced the situation). They made notes about field interviews during or shortly after the interviews took place. The researchers were careful not to interfere with 
social processes by only asking questions during field interviews in quiet one-on-one situations; for instance, when walking with a participant to a meeting or another ward.

\section{Formal interviews}

An intensive interview technique was used for the formal interviews with residents and supervisors. ${ }^{35}$ During the first half of the interview, we asked broad, open questions to allow the participants to speak freely (i.e. 'How do you experience your combined tasks of working as a physician and learning as a resident?' and 'How are your supervisory tasks facilitated?'). More directing questions about the CanMEDS and practice-based learning were asked during the second half of the interview (i.e. 'What, if anything, do you know about CanMEDS?' and 'How do you use CanMEDS when you are supervising residents?'). We would bring examples of the observational data into the interview (i.e. 'Could you reflect upon what happened during rounds, when your two supervisors told you to be more concise?'). The interviews lasted approximately 60 minutes. Interviews were audio recorded and transcribed verbatim.

\section{Analysis}

Data analysis started during the first fieldwork period and continued up to the writing of the results section. An inductive approach to data analysis was adopted in three successive steps: familiarization with the data, open coding to identify domains, and axial coding to identify connections between the domains and themes within them. Once the coding scheme had been refined, the complete dataset was analysed for relationships between themes and to explore the reasons for discrepant data. ${ }^{31,35}$ This study benefited from the research team's varied backgrounds in the analysis of the rich data and when making sense of the cultural characteristics of the clinical workplace. Discussions about what recurring patterns in the data meant, whether there were any tensions or interconnections between interpretations of situations, and how they relate to previous understandings took place between team members. These discussions were informed by the research team's professional experiences and insights from Communities of Practice theory into residents' identity formation, the clinical workplace community's shared regime of competence and how, mostly supervisors, negotiated about the meaning of CanMEDS. We sought to improve the study's rigour through constant comparison of our interpretations and coding. An explanatory theory was developed gradually through these continuous discussions. 


\section{$\underline{\text { Results }}$}

\section{Participants}

The practice-based training setting was observed for a total of 136 hours. Twelve residents and fourteen supervisors were included in the study. Their sub-specialties, experience and years spent in training are presented in Table 1.

-[Insert Table 1]-

\section{Presentation of results}

Three main aspects that we identified in our dataset were residents' activities, interactions, and organizational structures, which we now describe and illustrate with extracts from the interviews and field notes.

\section{CanMEDS and residents' activities}

The professional attitudes and behaviours advocated in the CanMEDS framework were ubiquitous in clinical practice. Residents typically combined aspects of multiple CanMEDS roles in their clinical activities. Consistent with the caveat noted by the initiators of CanMEDS that the roles are intertwined with one another, the roles were always closely integrated with one another. Health Advocate rarely occurred without Communicator and Medical Expert. Collaborator, Leader and Professional were generally intertwined in the Scholar and Medical Expert roles.

When residents encountered problems that fell within the roles of Leader (formerly Manager) and Health Advocate, their practice did not usually go beyond identifying the problems. More advanced aspects of these roles, such as 'initiating improvement and responding to needs of patients beyond the clinical environment', ${ }^{1}$ seemed to be beyond their reach. The latter is illustrated by the fragment below, in which the resident notes an issue in the Health Advocate role that her supervisor also seemed unable to solve.

A patient, released from the ward, explained that she had to walk back to the refugee camp she lived in, about 10 kilometres away, since she did not have money for a taxi. The 
resident reasoned that this was potentially harmful for the patient. She asked her supervisor whether the hospital could facilitate her return home. They reckoned there was no general arrangement for this.

Residents', and possibly even supervisors', positions within the hospital structure seemed too peripheral to take actions representing advanced aspects of the Leader role. The following fragment shows how a resident had to draw on such an aspect of the Leader role:

A weekly multidisciplinary meeting was scheduled at the ward. A resident noticed that it was inconvenient that the nurses were not present, because they had the most recent knowledge of the patients' status, and policy was being set based upon outdated information. He discussed this with the nurses, but they said they were too busy to attend. Later, during a formal interview, his supervisor stated that he had also tried to solve this problem, but had not succeeded so far.

\section{CanMEDS and interactions}

Interactions with other members of the Community of Practice, especially peers and supervisors, helped residents to define what they had learned from the activities they participated in. These interactions did not explicitly reflect the CanMEDS roles, but generally aligned well with the attitudes and behaviours advocated in them.

During a patient encounter, a patient told lively stories about herself. Afterwards, in the hallway, the resident said: 'Interesting stories... Why didn't you interrupt her?' Supervisor: 'Did you notice she told me about school in 1904 and how she met her husband in 1911? That was before she was born. Many residents ask patients to tell them where they are to test whether they are confused. But that can be uncomfortable for patients. Just letting patients tell their stories is often very revealing.'

As illustrated in the above example, CanMEDS roles usually remained implicit during supervisory interactions, even when the interactions were explicitly aimed at educating residents. The names of CanMEDS roles were rarely mentioned outside formal assessment situations: we heard a role being named only twice during the 136 hours of observations. In the fragment below, a supervisor discussed behaviours underlying multiple CanMEDS roles (Collaborator, Leader, Medical Expert) without mentioning them. 
A standard test indicated a bacterial infection. Further tests were needed to identify whether they had caused an infection. The resident said he wanted to admit the patient and treat the bacteria before the results returned. He asked a microbiologist for advice. Supervisor: 'The patient's urogenital system looks fine, but the microbiologist does not know that, and you obliged him to advise. These bacteria are everywhere, and the patient is feeling well. At this stage, you should not request help from microbiologists or pharmacists; that just needlessly increases the care costs. You have to make an educated guess based on the patient's status. They are not in charge of the patient, you are!'

The supervisors did not use the CanMEDS roles to discuss the residents' performance with each other either. Supervision was often handed over from one supervisor to the next in rather general language (i.e. 'She will not create a lot of work for you' or 'She really needs to know her facts better'). Other forms of discourses, such as evidence-based medicine and shared decision-making were, in contrast to the CanMEDS roles, part of the shared language and seemed more influential on practice-based learning.

\section{CanMEDS and organizational structure}

The residents' practice-based learning took place in an environment that was primarily focused on patient care. This focus at times caused friction between the various CanMEDS roles. For example, schedules seemed to be arranged mostly to serve the hospitals’ personnel planning, but impacted on practice-based learning. When residents were scheduled to attend at a ward for longer periods, the residents' studies and conversations with their supervisors were in-depth and concerned aspects of the various CanMEDS roles. When residents moved from one department to the next more quickly, however, attention shifted to what was most necessary and was often limited to the role of Medical Expert, discarding the others.

Resident during a field interview: 'I am scheduled at this ward for only one week. I am in survival mode right now. I barely have time to read up the patient records, let alone do any other work besides seeing patients. I just hope I will not make any serious mistakes in my diagnoses or treatments.'

Certain organizational artefacts seemed to impact on practice-based training. Electronic patient records were of particularly significant influence on which CanMEDS roles were discussed. During daily supervisory interactions, residents and supervisors would typically sit 
at a computer and go through patient records. The design of these records guided these conversations, and thus implicitly defined which roles were discussed. The three hospitals in the study used different patient record systems, meaning that the conversations between supervisors and residents were structured differently at each hospital. Certain patient record systems appeared to narrow the conversations strictly to Medical Expert, whereas others lead to the incorporation of a wider range of roles. The checklists for certain procedures or meetings also influenced these specific interactions. In one of the hospitals, all the meeting rooms had a checklist on the table. This checklist listed the topics to discuss for each patient (i.e. diagnosis, home situation, performing CPR if necessary or not). Meetings (i.e. multidisciplinary meetings, hand-overs) at which this checklist was used generally covered more CanMEDS roles than meetings without such a checklist.

\section{$\underline{\text { Discussion }}$}

\section{Principal findings and meaning}

This study has shown that in the settings studied, the CanMEDS framework did not really inform residents’ practice-based learning outside formal evaluation moments. In line with theory and previous studies, residents learned to take on professional roles through participation in activities and interactions with members of the community of practice. ${ }^{18,19}$ During these activities and interactions, CanMEDS roles were carried out in an integrated way and were not addressed explicitly. This is an important finding, since being explicit about what is expected of learners is considered to facilitate learning. ${ }^{36,37}$ Furthermore, the CanMEDS roles language was not adopted in the clinical workplace. At the same time, considerable differences between what types of behaviours individual supervisors expected from residents were ubiquitous. The lack of a shared language seemed to hamper the development of a regime of competence for resident performance, which is one of the key features of a Community of Practice. ${ }^{19}$ This is an interesting finding, since providing supervisors with a common language to reduce their cognitive load during teaching obligations is considered a major possible benefit of competency frameworks. ${ }^{38}$ In addition, this study has shown that although the clinical workplace was a very rich learning environment, certain organizational aspects, such as personnel planning and scheduling of 
meetings, occasionally interfered with residents' learning, as described in the CanMEDS framework.

\section{Theoretical interpretation}

The CanMEDS framework can be regarded as a social artefact developed in its creators' Community of Practice, which has travelled to other communities around the world. How the framework informs residents' practice-based training seems largely to depend on how it is adopted in the community. By negotiating the meaning of the CanMEDS roles, members of the community position it within their shared regime of competence. The extent to which the CanMEDS roles informed comprehensive practice-based training seemed rather limited within the Communities of Practice observed. The CanMEDS framework did not appear to guide the residents' activities or supervisory interactions outside formal assessment situations.

The names of the CanMEDS roles did not provide members of the community with a shared language to discuss resident performance, which might make the roles less useful than expected. This could be because the processes of negotiation of meaning could be facilitated better, but it may also relate to the intertwined nature of the roles. Even in the simple and brief activities we observed, the residents had to draw on aspects of multiple roles at the same time. This makes determining where a certain role ends and where others begin rather unclear, which could make them less useful for explicit teaching.

CanMEDS roles sometimes seemed to be a description of an ideal world, which did not align well with the reality of clinical practice. Although most activities and interactions were in line with the practice described in the CanMEDS framework, the residents', and perhaps even the supervisors', roles within the hospital organization seemed too peripheral to cause actions that reflect advanced behaviours falling within especially the Leader and Health Advocate roles. The physicians’ agency seemed to be more limited by hospital structure in those roles, compared to what is described in the framework. Furthermore, this 'ideal' practice that the CanMEDS framework described seemed to contradict other informative, organizational elements within the community. CanMEDS roles were only one of many factors that influence practice-based training.

\section{Strengths and limitations}


The data for this study were collected through a rigorous combination of direct observation and in-depth participant interviews. Observational research is, however, often criticised for being prone to observer effects. There is a risk that our presence may have affected the behaviour of our participants. By investing in the relationship with our participants while interfering with the social situation as little as possible, we aimed to mitigate effects on participants’ behaviour. ${ }^{39}$

Communities of Practice theory provided useful analytical lens for this study. The concepts of identity, regime of competence and negotiation of meaning helped us study reflexively how CanMEDS informs residents' practice-based learning. A boundary of Communities of Practice theory in this study may be that it does not explicitly signify assessment as highly influential for practice-based learning, whereas within the medical education domain assessment is generally accepted to be one of the most powerful learning tools. The interpretation of practice-based learning would have been more assessment-oriented if we had taken on a more behaviouristic orientation. Using sensitising insights from Communities of Practice theory directed us towards meaningful interactions between residents, supervisors and residents and patients and residents, which are considered highly influential for residents' learning.

The professional but non-medical background of the observers helped them approach practice-based learning with open minds and to ask questions about aspects which others might have taken for granted. By profiting from our various professional backgrounds and perspectives on the data during interpretations, we feel it is reasonable to draw the conclusions arrived at based on the data obtained. Rather than presenting generalizable results, we aim to present professional situations that others will recognise, and believe our critical interpretations will contribute meaningfully to the on going debate about outcomesbased residency training.

Although the findings presented in this paper apply to all three of the contexts observed, there is no guarantee that they are transferable to other settings. The authors aimed to increase the study's rigour by incorporating multiple sites. This was limited, however, to internal medicine departments in a Dutch context. It is therefore up to the readers to assess how the theoretical constructs arrived at apply to their specific setting. It is conceivable that some of the findings 
are typical of all clinical settings, but we have also experienced that the organizational context, a very local factor, is of major importance for practice-based learning.

\section{Implications for practice and future research}

In order to maximize the possible benefits of competency frameworks, they should be aligned better with comprehensive clinical practice. It appears that the terms of the CanMEDS framework need to reflect the reality of clinical practice better. At the level of interactions between supervisors and residents, this means that the adoption of CanMEDS roles as a common language to discuss competence might make tacit messages more explicit. At the level of supervisors discussing amongst themselves, a common language could facilitate negotiation of meaning and deliberate supervisory handovers, and therefore increase continuity in the residents' learning. At the hospital level, the impact that organizational aspects such as schedules and patient records have on resident learning should not be underestimated. Aligning these organizational aspects with the CanMEDS framework may result in more beneficial effects being derived from competency-based training. At the level of the CanMEDS roles being used as an educational innovation, careful observation of the clinical practice of a specific context and adjusting the names of the roles accordingly could be beneficial. Furthermore, this study's findings regarding the integration of CanMEDS roles in clinical practice could contribute to the empirical underpinnings of implementing Entrustable Professional Activities (EPA) ${ }^{40}$ Using a comprehensive clinical activity as the basis for assessment instead of a combination of multiple CanMEDS roles might indeed better align with the reality of practice-based learning.

\section{$\underline{\text { Conclusion }}$}

A competency framework, in this case CanMEDS, seems to be only one of many artefacts that influence how residents learn in a Community of Practice. Although many supervisory interactions were in line with what the initiators of CanMEDS might have intended, the framework does not appear to guide supervisors or residents. It is therefore questionable whether the implementation of CanMEDS-based training has caused a shift in practice, or whether the CanMEDS framework simply fitted a practice that was already changing in that direction. Although CanMEDS may be an appropriate tool for assessment of residents’ 
professional performance, it seems less useful to guide comprehensive practice-based training. 


\section{References}

1. Frank JR, Snell L, Sherbino J, editors. The Draft CanMeds 2015 Physician Competency Framework - Series IV. Ottawa: The Royal College of Physicians and Surgeons of Canada; 2015.

2. Frank JR, Danoff D. The CanMEDS initiative: implementing an outcomes-based framework of physician competencies. Med Teach 2007;29(7):642-647.

3. Carraccio C, Wolfsthal SD, Englander R, Ferentz K, Martin C. Shifting paradigms: From Flexner to competencies. Acad Med 2002;77(5):361-367.

4. Hodges BD, Kuper A. Theory and practice in the design and conduct of graduate medical education. Acad Med 2012;87(1):25-33.

5. Malone K, Supri S. A critical time for medical education: the perils of competencebased reform of the curriculum. Adv Health Sci Educ 2012;17(2):241-246.

6. Hawkins RE, Welcher CM, Holmboe ES, Kirk LM, Norcini JJ, Simons KB, et al. Implementation of competency-based medical education: are we addressing the concerns and challenges? Med Educ 2015;49(11):1086-102.

7. Taber S, Frank JR, Harris KA, Glasgow NJ, Iobst W, Talbot M, et al. Identifying the policy implications of competency-based education. Med Teach 2010;32(8):687-691.

8. Frank JR, Snell LS, Ten Cate O, Holmboe ES, Carraccio C, Swing SR, et al. Competency-based medical education: theory to practice. Med Teach 2010;32(8):638645.

9. Holmboe ES, Sherbino J, Long DM, Swing SR, Frank JR, Int CBME Collaborators. The role of assessment in competency-based medical education. Med Teach 2010;32(8):676-682.

10. Schuwirth LWT, Van der Vleuten CPM. Programmatic assessment: From assessment of learning to assessment for learning. Med Teach 2011;33(6):478-485.

11. Goldszmidt M, Dornan T, Lingard L. Progressive collaborative refinement on teams: implications for communication practices. Med Educ 2014;48(3):301-314.

12. Kennedy TJT, Regehr G, Baker GR, Lingard LA. Progressive independence in clinical training: A tradition worth defending? Acad Med 2005;80(10):S106-S111.

13. Prideaux D, Alexander H, Bower A, Dacre J, Haist S, Jolly B, et al. Clinical teaching: maintaining an educational role for doctors in the new health care environment. Med Educ 2000;34(10):820-826.

14. Steven K, Wenger E, Boshuizen H, Scherpbier A, Dornan T. How Clerkship Students Learn From Real Patients in Practice Settings. Acad Med 2014;89(3):469-476

15. Tynjala P. Toward a 3-P Model of Workplace Learning: a Literature Review. Vocat Learn 2013;6(1):11-36. 
16. Parboosingh JT. Physician communities of practice: where learning and practice are inseparable. J Contin Educ Health Prof 2002;22(4):230-236.

17. Turner SR, White JS, Poth C, Rogers WT. Learning the CanMEDS roles in a nearpeer shadowing program: A mixed methods randomized control trial. Med Teach 2012;34(11):888-892.

18. Teunissen PW, Scheele F, Scherpbier AJJA, van der Vleuten CPM, Boor K, van Luijk SJ, et al. How residents learn: qualitative evidence for the pivotal role of clinical activities. Med Educ 2007;41(8):763-770.

19. Wenger E. Communities of practice: learning, meaning, and identity. Cambridge, UK: Cambridge University Press; 1998.

20. Van der Lee N, Fokkema JPI, Westerman M, Driessen EW, van der Vleuten CPM, Scherpbier AJJA, et al. The CanMEDS framework: Relevant but not quite the whole story. Med Teach 2013;35(11):949-955.

21. Chou S, Cole G, McLaughlin K, Lockyer J. CanMEDS evaluation in Canadian postgraduate training programmes: tools used and programme director satisfaction. Med Educ 2008;42(9):879-886.

22. Renting N, Gans ROB, Borleffs JCC, Van Der Wal MA, Jaarsma ADC, CohenSchotanus J. A feedback system in residency to evaluate CanMEDS roles and provide high-quality feedback: Exploring its application. Med Teach 2016; 38(7):738-45.

23. Ginsburg S, McIlroy J, Oulanova O, Eva K, Regehr G. Toward Authentic Clinical Evaluation: Pitfalls in the Pursuit of Competency. Acad Med 2010;85(5):780-786.

24. Merenstein JH, Schulte JJ. A residency curriculum for the future. The STFM Task Force on Residency Curriculum for the Future. Fam Med 1990;22(6):467-73.

25. Renting N, Dornan T, Gans ROB, Borleffs JCC, Cohen-Schotanus J, Jaarsma ADC. What supervisors say in their feedback: construction of CanMEDS roles in workplace settings. Adv Health Sci Educ 2016; 21(2): 375-387.

26. Mann KV. Theoretical perspectives in medical education: past experience and future possibilities. Med Educ 2011 JAN;45(1):60-68.

27. Egan T, Jaye C. Communities of clinical practice: the social organization of clinical learning. Health 2009 JAN;13(1):107-125.

28. Swanwick T. Informal learning in postgraduate medical education: from cognitivism to 'culturism'. Med Educ 200;39(8):859-865.

29. Lyon P. A model of teaching and learning in the operating theatre. Med Educ 2004;38(12):1278-1287.

30. Lyon PMA. Making the most of learning in the operating theatre: student strategies and curricular initiatives. Med Educ 2003;37(8):680-688. 
31. Charmaz K. Constructing grounded theory. 2nd edn. London, UK: Sage; 2014.

32. Speelman P, Slaets JPJ, de Graaf J, van Saase JLCM, Smulders YM, van der Helm HMJ, Cloesmeijer WE, editors. Opleidingsplan Interne Geneeskunde. Nederlandse Internisten Vereniging; 2009.

33. Morcke AM, Dornan T, Eika B. Outcome (competency) based education: an exploration of its origins, theoretical basis, and empirical evidenc. Adv Health Sci Ed 2013; 18(4):851-63.

34. Hammersley M, Atkinson P. Ethnography: principles in practice. 3rd edn, London, UK: Routledge; 2010.

35. Strauss A, Corbin JM. Grounded theory in practice. London, UK: Sage; 1997.

36. Swanwick T. Informal learning in postgraduate medical education: from cognitivism to 'culturism'. Med Educ 2005; 39:859-856.

37. Eraut M. Non-formal learning and tacit knowledge in professional work. Brit J Educ Psy 2000; 70: 113-136.

38. Kogan JR, Conforti LN, Bernabeo E, Iobst W, Holmboe E. How faculty members experience workplace-based assessment rater training: a qualitative study. Med Educ 2015; 49(7): 692-708.

39. Paradis E \& Sutkin G. Beyond a good story: from Hawthore Effects to reactivity in health professions education research. Med Educ 2017; 51(1):31-39.

40. Ten Cate, O. Entrustability of professional activities and competency-based training. Med Educ 2005; 39(12): 1176-1177. 
Table 1. Participant Characteristics

\begin{tabular}{llllll}
\hline \multicolumn{2}{l}{ RESIDENTS } & Field & Formal & \\
Gender & Year & Observed & $\begin{array}{l}\text { interview } \\
\text { interview }\end{array}$ & Specialty \\
\hline F & 1 & Ward & Y & Y & Hospital \\
F & 2 & Ward & Y & G & General Internal \\
M & 3 & Ward, ER & Y & Y & Cardiology \\
M & 1 & Ward, ER & Y & Y & General Internal \\
F & 2 & Ward, ER & Y & Y & Pulmonology \\
M & 2 & Ward & Y & Y & Cardiology \\
F & 4 & Policlinic & Y & N & General Internal \\
F & 1 & Ward, ER & Y & N & Rheumatology \\
F & 1 & Ward & Y & N & Cardiology \\
M & 3 & Policlinic & Y & Y & General Internal \\
F & 2 & Ward, ER & Y & N & Hospital \\
F & 3 & Ward, Policlinic & Y & N & Pulmonology \\
\hline M: Male & Experience in & Setting of & Y: Yes & Y: Yes & Residents' area of \\
F: Female & years & observation & N: No & N: No & specialization
\end{tabular}

\section{SUPERVISORS}

\begin{tabular}{llllll} 
Gender & Experience & Observed & $\begin{array}{l}\text { Field } \\
\text { interview }\end{array}$ & $\begin{array}{l}\text { Formal } \\
\text { interview }\end{array}$ & Specialty \\
\hline M & $>20$ & Ward & Y & Y & Nephrology \\
M & $5-10$ & Ward & Y & Y & Vascular \\
M & $>20$ & Ward & Y & Y & Gascular \\
F & $5-10$ & Ward & Y & G & Endatrics \\
M & $15-20$ & Ward, ER, & Y & Y & \\
& & Policlinic & & & Nephrology \\
F & $0-5$ & Ward, ER & Y & Y & Nephrology \\
M & $5-10$ & Ward, ER & Y & N & Nephrology \\
M & $>20$ & Ward, Policlinic & Y & Y & Nephrology \\
F & $10-15$ & Ward & Y & N & General Internal \\
M & $15-20$ & Ward, Policlinic & Y & Y & Geriatrics \\
F & $10-15$ & Ward & Y & N & Nephrology \\
M & $15-20$ & Ward & Y & N & Endocrinology \\
F & $15-20$ & Ward & N & N & Infectious disease \\
M & $10-15$ & Ward, Policlinic & Y & Y & Supervisors' area of \\
\hline M: Male & Experience in & Setting of & Y: Yes & Y: Yes & specialization
\end{tabular}

